\title{
Product Conceptual Design Modeling: A NeW Generalized Algorithm
}

\author{
Diaconescu, D.; Jaliu, C.; NeAgoe, M. \& SAulescu, R.
}

Abstract: Based on a comparative analysis of the conceptual design algorithms proposed in literature, a new variant of the conceptual design modeling, whose algorithm generalizes the existing algorithms, is proposed in the paper. The structure of the generalized algorithm starts from the requirements list and contains: a) global function statement, b) global function description by structures of sub-functions, $c$ ) solving structures generation, and d) selection of the best solving structure (the concept) by evaluation.

Key words: conceptual design, product concept, generalized algorithm
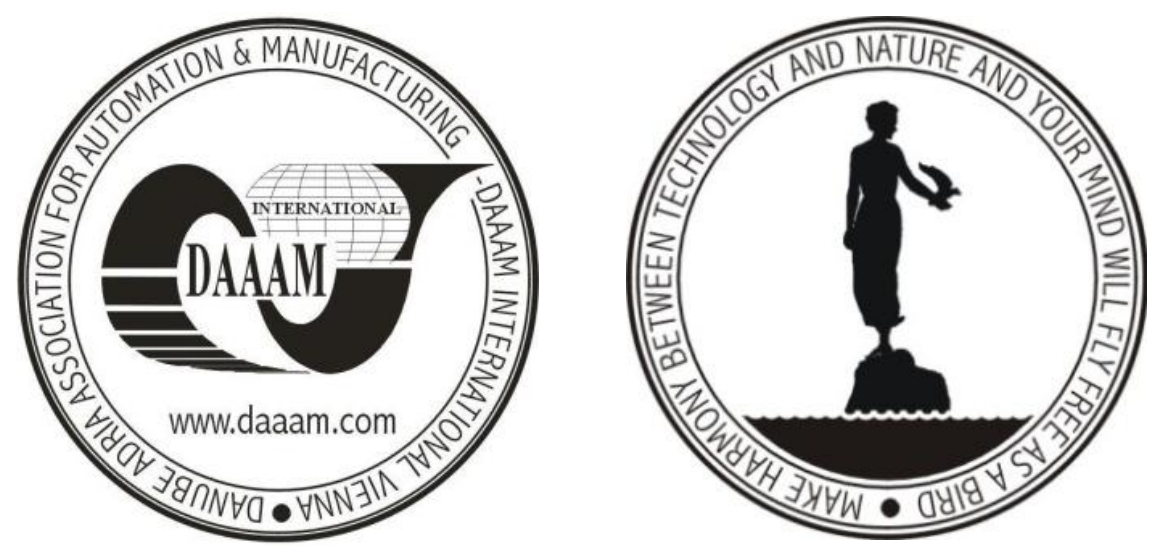

Authors' data: Univ.Prof. Dipl.-Eng. Dr. Diaconescu, D[orin]; Univ.Prof. Dipl.Eng. Dr. Jaliu, C[odruta]; Univ.Prof. Dipl.-Eng. Dr. Neagoe, M[ircea]; Univ.Lecturer Dipl.-Eng. Dr. Saulescu, R[adu], Transilvania University of Brasov, Eroilor 29, 500036, Brasov, Romania, dvdiaconescu@unitbv.ro, cjaliu@unitbv.ro, mneagoe@unitbv.ro, rsaulescu@unitbv.ro.

This Publication has to be referred as: Diaconescu, D[orin]; Jaliu, C[odruta]; Neagoe, M[ircea] \& Saulescu, R[adu] (2010). Product Conceptual Design Modeling : A new Generalized Algorithm, Chapter 53 in DAAAM International Scientific Book 2010, pp. 607-616, B. Katalinic (Ed.), Published by DAAAM International, ISBN 978-3-901509-74-2, ISSN 1726-9687, Vienna, Austria

DOI: $10.2507 /$ daaam.scibook.2010.53 
Diaconescu, D.; Jaliu, C.; Neagoe, M. \& Saulescu, R.: Product Conceptual Design ...

\section{Introduction}

The conceptual design denomination is derived from the older notion of product concept, used for the result of this design. The new terminology promotes the denomination of the product principle solution instead of the concept notion; momentary both notions coexist in literature.

Based on a comparative analysis of the algorithms that are proposed in literature, the authors propose a new variant of the product conceptual design modeling, whose algorithm generalizes the existing algorithms.

\section{Comparative analysis of the existing conceptual design models}

Several models for conceptual design modeling are proposed in literature. The most representative belong to Cross (Cross, 1994), Ulrich \& Eppinger (Ulrich \& Eppinger, 2008); Dieter \& Schmidt (Dieter \& Schmidt, 2009), Pahl et al. (Pahl et al., 2007) and VDI (VDI, 1997). From the comparative analysis of these models, some useful conclusions come out, detailed in the following subsections.

\subsection{On the requirements list elaboration}

Unlike the first three mentioned models (Cross, 1994; Ulrich \& Eppinger, 2008; Dieter \& Schmidt, 2009), in which the requirements list is considered a step of the conceptual design, the requirements list is input entity in the German models (Pahl et al., 2007; VDI, 1997); therefore, in the German view, the requirements list is a distinct activity, relatively autonomous, with objectives and approach methods different from those of the properly conceptual design. Instead of requirement's list, in the English literature it is met the abbr. PDS (Product Design Specification) or the more simple denomination of specification.

\subsection{On the strictness of terminology}

From the analysis of the used terminology in the mentioned models, some interesting observations come out:

- Cross's model (Cross, 1994) uses a terminology of general type, like: objective, problem and sub-problem, function and sub-function, requirement, characteristic, alternative (variant), sub-solution, solution, etc.

- The models of the American authors, Ulrich \& Eppinger (Ulrich \& Eppinger, 2008) and Dieter \& Schmidt (Dieter \& Schmidt, 2009), use a more elaborated terminology which has also specialized notions, like: target specification, product concept, concept development, the concept of a sub-problem, integrated solution, project development, etc.

- The German models use the most rigorous terminology, and between them, the VDI model (VDI, 1997) has the most accurate form. Beside the general notions, there are used strictly specialized notions as: structure of functions, solving principle, physical effect, effect carriers, configurations of the effect carriers, solving structure, principle solution, effects plan, configuration plan, etc. 


\subsection{On the models' common denominator}

Though they have different formulations, all the mentioned design models can be reduced, through abstracting and simplifying, to the same common denominator, illustrated through the algorithm from Fig. 1 (adapted after VDI 2221); in fact, this

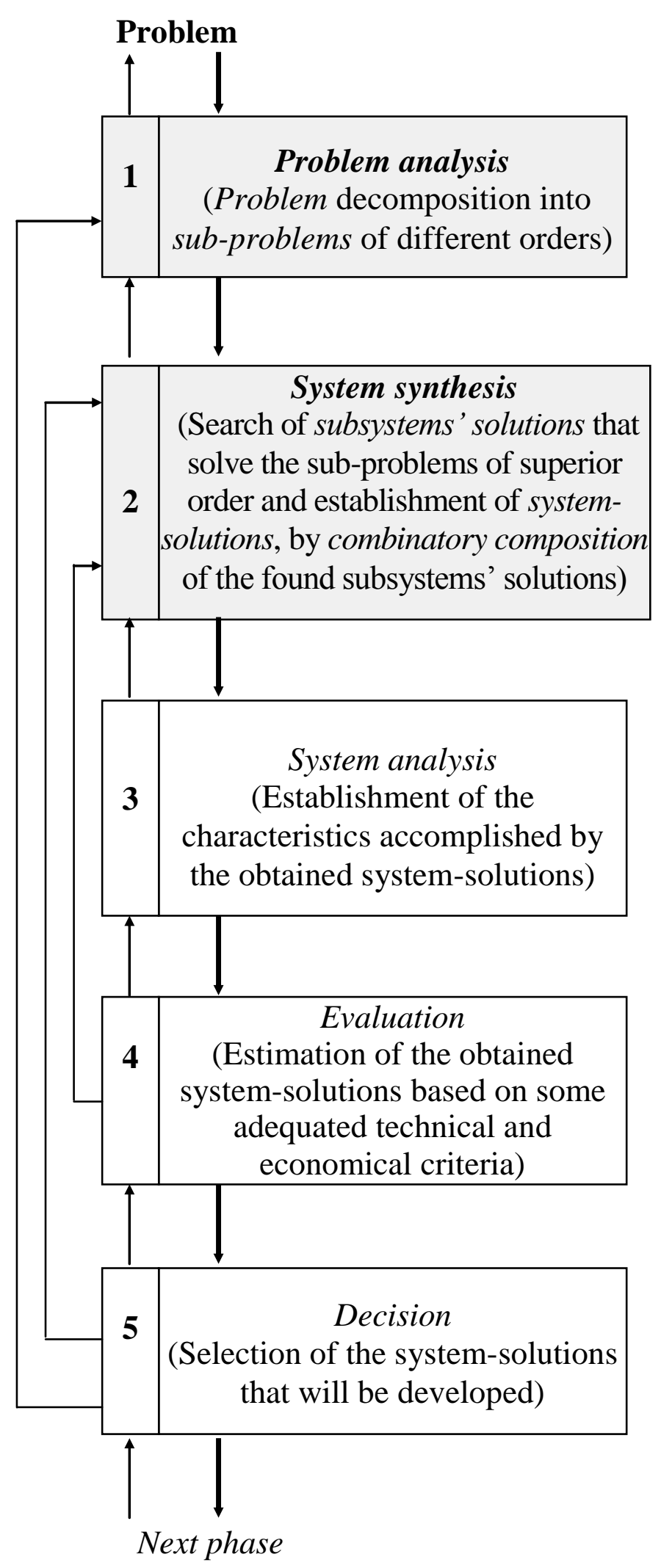

Fig. 1. The solving structure of a technical problem (adapted after VDI 2221)
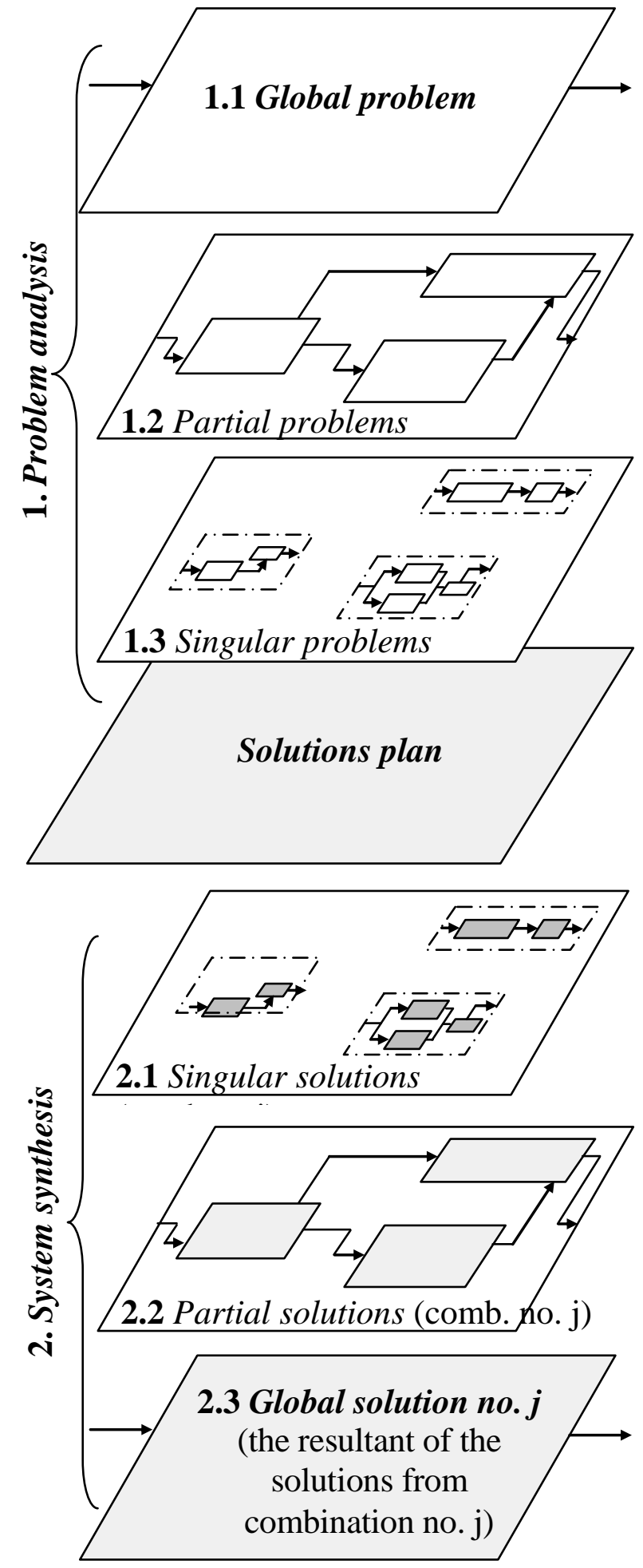

Fig. 2. The solving structure of a technical problem by its dividing into sub-problems and composing the subsolutions from different combinations (adapted after VDI 2221) 
Diaconescu, D.; Jaliu, C.; Neagoe, M. \& Saulescu, R.: Product Conceptual Design ...

algorithm designates the solving cycle of a technical problem, in five steps. Through the oriented lines from Fig. 1 there are designated the information flows between steps: the main flow is represented with a thick line, while the inverse iterative flows (necessary in correction and optimization) are traced with a thin line. According to the German view, in solving the technical problems, the steps no. 1 and no. 2 can be structured following an algorithm like the one from Fig. 2 (adapted after VDI 2221), which consists of six main sub-steps $(1.1, \ldots, 2.3)$.

All the mentioned design models can be reduced, through simplification, to the same common denominator: the algorithm for solving cycle of a technical problem. This algorithm can be found in the simplified variant of the type: global problem $\rightarrow$ sub-problems $\rightarrow$ sub-solutions $\rightarrow$ global solution in the structure of each design model that was previously mentioned.

\section{Generalized algorithm}

Starting from the product design variant modeled in Fig. 3, a new variant that models the product conceptual design is proposed in Fig. 4, derived from the previous

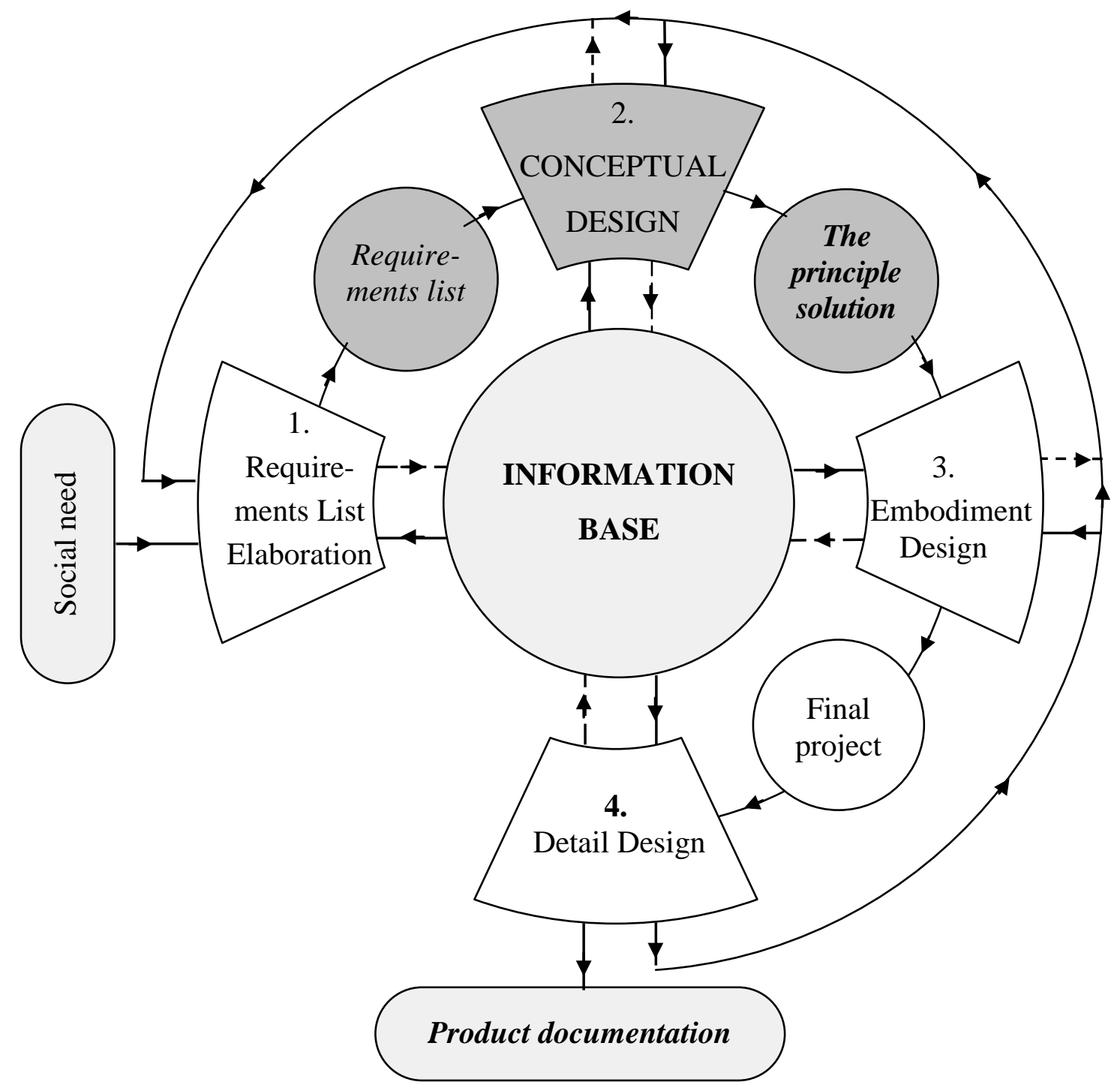

Fig. 3. Generalized algorithm of the Product Design process 
mentioned models by generalization. The structure of the generalized algorithm from Fig. 4 is centered on an adequate base of information, starts from a requirements list and contains and contains four steps and four main results:

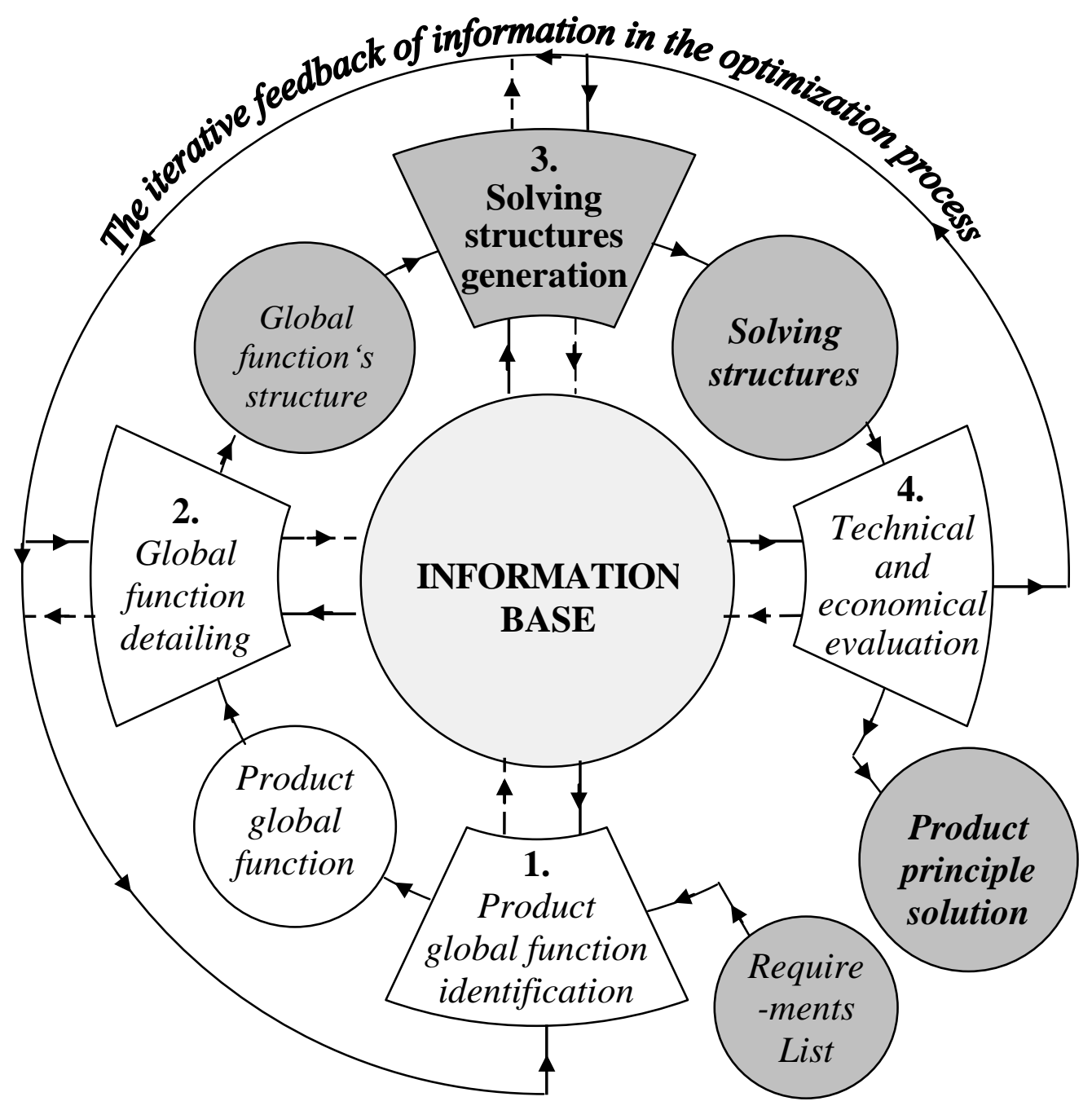

Fig. 4. Generalized algorithm of the conceptual design

1. Global function statement. Result: The global function,

2. Global function description by structures of sub-functions, of different orders. Result: The structure of the global function,

3. Solving structures generation by: solving the sub-functions, sub-solutions composition and elimination of the inadequate solutions. The solving structures are established by determining and analyzing the characteristics of each obtained variant, followed by the elimination of the variants that do not fulfill quantitatively the requirements from the list. Result: Solving structures,

4. The best solving structure selection by a technical and economical evaluation. Result: The product principle solution (the concept).

The inverse connections between steps (Fig. 4), which are necessary in the iterative optimization and in readapting the requirements list, can be made directly, through the peripheral information flow, or indirectly through the information base.

Among the four steps (Fig. 4), the solving structures generation (step 3) represents the key step; for this step, illustrated in Fig. 4 in a shaded shape, a general algorithm was 
detailed in Fig. 5. This algorithm (Diaconescu et al., 2008), derived from the homonymous algorithm proposed by Ulrich and Eppinger (Ulrich \& Eppinger, 2008) considering the VDI terminology, is centered on an adequate information base, starts from a known structure of sub-functions and contains (see Fig. 5):

$1^{\circ}$. Grouping of the sub-functions into: a) functions of U.S.P. type (Unknown Solving Principles) and b) functions of K.S.P. type (Known Solving Principles). Results: Functions of U.S.P. type and functions of K.S.P. type.

$2^{\circ}$. Solving principles synthesis (for U.S.P. functions and for the K.S.P. functions whose existent solutions are unsatisfactory for the designed or developed product), i.e. synthesis of physical effects and configuration of effects carriers, followed, for composed sub-functions, by the composition of the partial solutions. Result: New solving principles.

$3^{\circ}$. Identification of known solutions. Result: existent solutions.

$4^{\circ}$. Generation of the solving structures, which contains:

$4.1^{\circ}$ solving structural variants generation by a combinatory composition of the compatible solutions from steps $2^{\circ}$ and $3^{\circ}$, and

$4.2^{\circ}$ a) initial configuration (geometrical-kinematical synthesis) of the obtained variants; b) pre-establishing the main technical characteristics of these variants; c) then, eliminating the structural variants whose technical characteristics don't satisfy quantitatively the requirements (main objectives) from the requirements list. Result: solving structures.

Hence, a solving structure is a structural variant that solves the product global function, according to the main objectives from the requirements list, both qualitatively and quantitatively. In solving steps $1^{\circ} \ldots 3^{\circ}$, a decisive role is played by the information base and the experience of the design.

In the case of the K.S.P. functions, the identification of the existent solutions is based on two main sources: the technical literature and the existent technical systems.

The present information sources from literature are referring to: technical and economical periodicals, bulletins and magazines from the research field; monographs and academic courses, reference bulletins, dictionaries, lexicons and encyclopedias, mathematical and technical agendas, $\mathrm{PhD}$ thesis, research projects, legislative norms, technical norms and standards, patents, design catalogues (catalogues of physical effects, catalogues of principle solutions for usual functions, catalogues of constructive solutions etc.), catalogues and prospects of products (edited by the producer companies and/or sale companies), scientific, technical and economical reports, elaborated by different institutions and associations, web-sites in the field etc.

For the U.S.P. functions, the physical effects and/or the configuration of the effects' carriers can be found by: conventional methods (e.g. analysis of the natural systems, models analogy, testing and measurement, etc.), intuitive methods (e.g.: Delphi method, Brainstorming, 635 method, Gallery method, Synectics, etc.) and logical methods (e.g modeling and numerical simulation of physical processes, systematical search by using matrixes and catalogues of physical effects, the variation of the effects' carriers configuration for known solutions, etc.). 


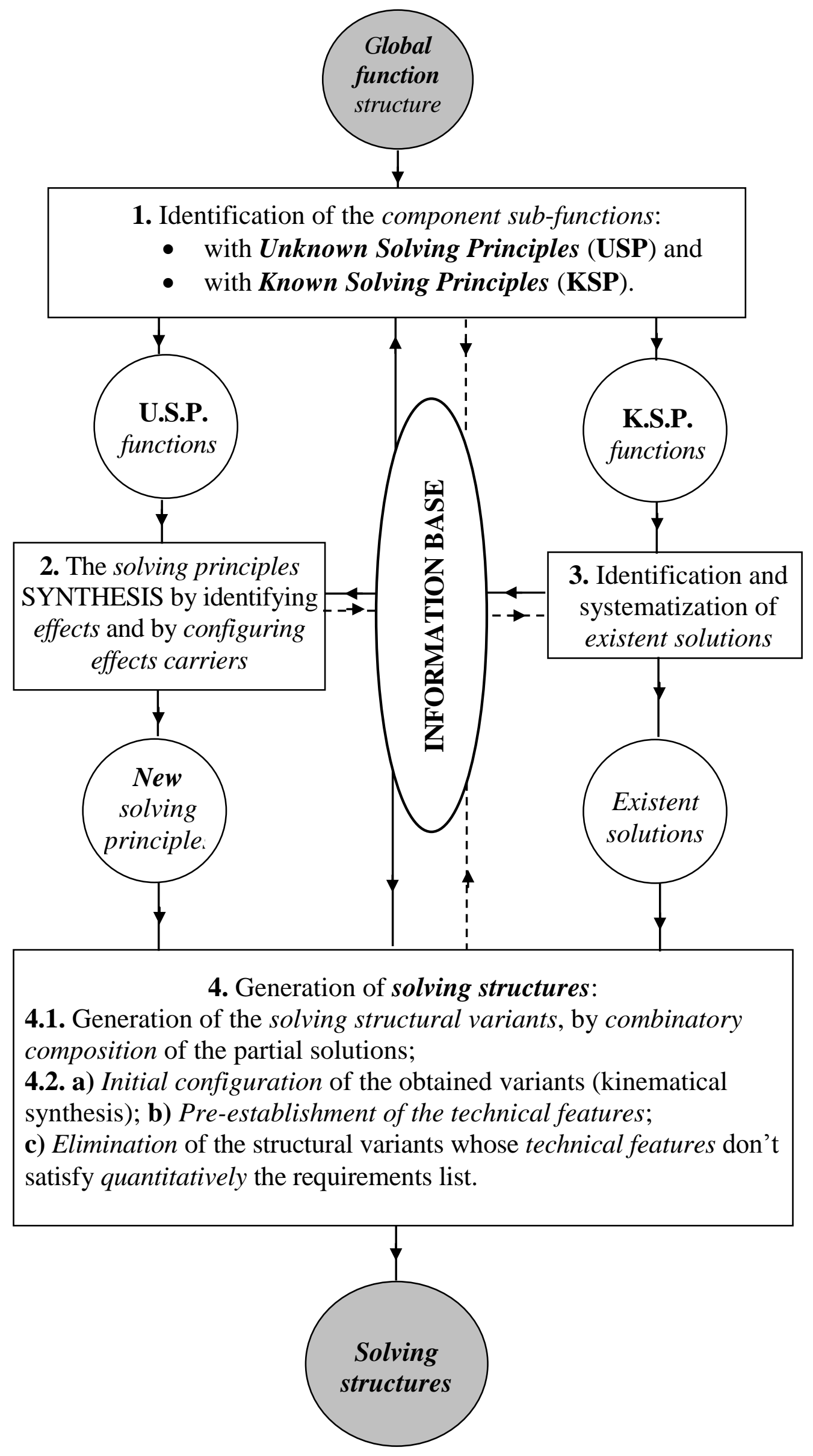

Fig. 5. Algorithm of solving structures generation (step 3 from Fig. 4) 
Diaconescu, D.; Jaliu, C.; Neagoe, M. \& Saulescu, R.: Product Conceptual Design ...

The generation of solving structural variants, through combining and composing the partial solutions (sub-step 4.1 from Fig. 5), can be done using mathematical combining methods or morphological matrixes (VDI, 1997); between them, the second alternative is the most used.

In terms of novelty, from the global function of a product can come out more design types and variants (Dieter \& Schmidt, 2009; Otto \& Wood, 2001; Pahl et al., 2007), systematized in Table 1:

\begin{tabular}{|c|c|c|c|}
\hline \multirow{3}{*}{\begin{tabular}{l}
\multicolumn{1}{|c}{ The sub-functions } \\
The solutions contain \\
global function \\
structure contains
\end{tabular}} & \multicolumn{3}{|c|}{ Solving principles } \\
\hline & \multirow[b]{2}{*}{ new } & \multicolumn{2}{|c|}{ known } \\
\hline & & $\begin{array}{c}\text { With RE- } \\
\text { configuration }\end{array}$ & $\begin{array}{l}\text { In the existent } \\
\text { configuration }\end{array}$ \\
\hline \multirow{3}{*}{ New connections } & \multirow{2}{*}{$\begin{array}{l}\text { O.D. } \\
\text { type I }\end{array}$} & O.D. type V & O.D. type VII \\
\hline & & \multicolumn{2}{|c|}{ O.D. type VI } \\
\hline & \multicolumn{3}{|c|}{ O.D. type II } \\
\hline \multirow{3}{*}{ Known connections } & \multirow{2}{*}{$\begin{array}{l}\text { O.D. type } \\
\text { III }\end{array}$} & A.D. type I & V.D. \\
\hline & & \multicolumn{2}{|c|}{ A.D. type II } \\
\hline & \multicolumn{3}{|c|}{ O.D. type IV } \\
\hline
\end{tabular}

Tab. 1. Design types and variants

1) Original design (OD), with seven distinct variants (OD-I, .., OD-VII),

2) Adaptive design (AD), with two distinct variants (AD-I and AD-II) and

3) Variant design (VD), with a single alternative.

The following differences derive from Table 1:

- in the original design, the principle solution contains elements of originality at least in the effects plan or at least in the connections plan;

- in the adaptive design, the principle solution brings elements of novelty only regarding the configuration of the effects' carriers,

- in the variant design, the principle solution is known in all the three plans: of effects, of the effects' carriers' configurations and of connections; therefore, the variant design is a form of embodiment design through similitude (by using a ,pattern“); in (Dieter \& Schmidt, 2009), this design type in named also modification.

Beside these design types, can be added (Dieter \& Schmidt, 2009):

4) Select design, which is a selection of the needed components, from the firm catalogs, after: performances and costs.

\section{Conclusions}

The following conclusions can be formulated based on the presented algorithms from Fig. 3, 4 and 5:

- Each step from Fig. 3 represents a distinct activity, relatively autonomous, with its own notions and methods. 


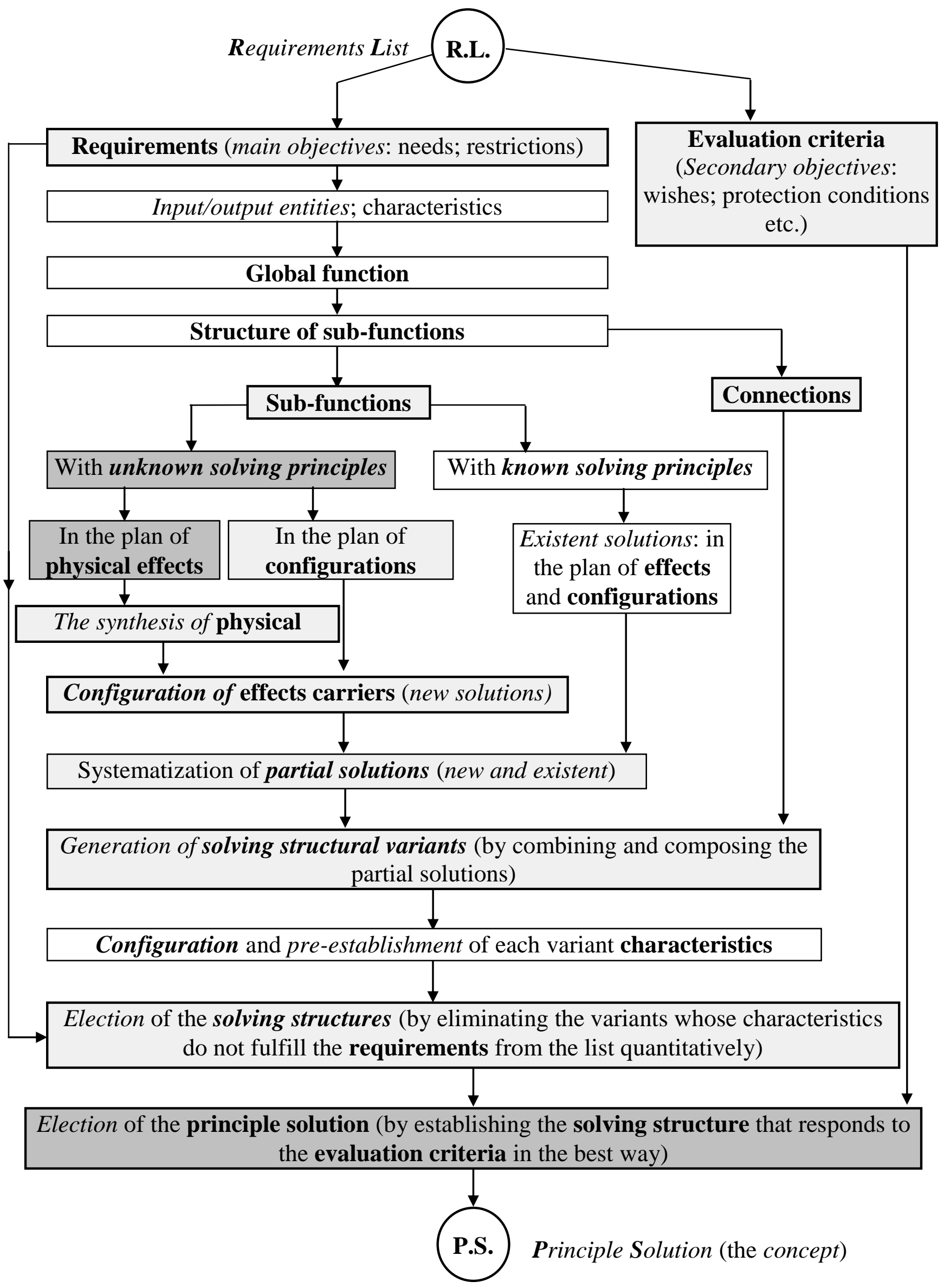

Fig. 6. Detailling of the conceptual design algorithm from Fig. 4 
- In order to create an intuitive and unitary image on the hierarchy and correlations between the notions that are used, a simplified and synthetic variant of the algorithms from Fig. 4 and 5 was proposed in Fig. 6.

- According to Fig. 4 and Fig. 5, the global function of a product has elements of novelty if: b1) it has at least one U.S.P. function and/or if: b2) at least one original connection interferes in the global function structure.

- In terms of novelty, more design types can come out from the global function of a product (Pahl et al., 2007): 1) Original design, 2) Adaptive design and 3) Variant design; in each of them, the principle solution contains: 1) elements of originality at least in the plan of effects or at least in the plan of connections; 2) elements of novelty only regarding the configuration of the effects carriers; 3) known effects, known effects carriers configurations and known connections; therefore, the variant design is a form of design through similitude (by the „model"); 4) Select design, which is a selection of the needed components, from the firm catalogs, after: performances and costs (Dieter \& Schmidt, 2009).

\section{Acknowledgement}

The authors will accomplish the design, manufacturing and testing of the speed increaser for stand-alone hydropower stations in the framework of the research project "Innovative mechatronic systems for micro hydrostations, meant to the efficient exploitation of hydrological potential from off-grid sites", ID_140. The preparation and publishing of this paper would not have been possible without the financial support of this research project.

\section{References}

Cross, N. (1994). Engineering Design Methods, J. Wiley \& Sons, ISBN 0-47194228-6, New York

Diaconescu, D.; Neagoe, M.; Jaliu, C. \& Săulescu, R. (2008). Products' Conceptual Design, Transilvania University Publishing House, ISBN 978-973-598-230-0, Brasov

Dieter, G. \& Schmidt, L. (2009). Engineering Design, Fourth edition, McGraw Hill, ISBN 978-007-126341-2, Boston

Otto, K.N. \& Wood, K.L. (2001). Product Design: Techniques in Reverse Engineering and New Product Development, Prentice Hall, New Jersey 07458

Pahl, G.; Beitz, W.; Feldhusen, J. \& Grote, K.H. (2007). Engineering Design: A systematic approach, Third edition, Springer-Verlag, ISBN 978-1-84628-318-5 Ulrich, K. \& Epinger, S. (2008). Product Design and Development, Fourth edition, McGraw-Hill Inc., ISBN 978-007-125947-7, Boston

*** VDI - Verein Deutscher Ingenieure (1997). Richtlinien 2221 and 2222 